\title{
"In-Bore" MRI-Guided Prostate Biopsy for Prostate Cancer Diagnosis: Results from 140 Consecutive Patients
}

\author{
Daniele D'Agostino ${ }^{a}$ Daniele Romagnolia Marco Giampaolia Federico Mineo Bianchi ${ }^{b}$ \\ Paolo Corsi $^{\mathrm{a}} \quad$ Alessandro Del Rosso $^{\mathrm{a}}$ Riccardo Schiavina ${ }^{\mathrm{b}}$ Eugenio Brunocilla ${ }^{\mathrm{b}}$ \\ Walter Artibani ${ }^{\mathrm{a}}$ Angelo Porreca ${ }^{\mathrm{a}}$ \\ aDepartment of Robotic Urological Surgery, Abano Terme Hospital, Abano Terme; bepartment of Urology, University of Bologna, Bologna, \\ Italy
}

\section{Key Words \\ Prostate biopsy • Multiparametric magnetic resonance • \\ Prostate cancer • Prostate cancer detection • \\ Transrectal ultrasound-guided prostate biopsy}

\begin{abstract}
Objectives: Transrectal ultrasound-guided biopsy (TRUS-GB) is the current reference standard procedure for diagnosis of prostate cancer ( $\mathrm{PCa}$ ) but this procedure has limitations related to the low detection rate (DR) described in the literature. The aim of the study was to evaluate the DR efficiency, and complication rate in a pure "in-bore" magnetic resonance imaging-guided biopsy (MRI-GB) series according to the Prostate Imaging Reporting and Data System, version 2 (PI-RADS v2). Materials and Methods: From July 2015 to April 2018, a series of 142 consecutive patients undergoing MRI-GB were prospectively enrolled. According to the European Society of Urogenital Radiology guidelines, the presence of clinically significant PCa (csPCa) on multiparametric magnetic resonance imaging was defined as equivocal, likely, or highly likely according to a PI-RADS v2, score of 3, 4, or 5, respectively. Results: Of 142 patients, 76 (53.5\%) were biopsy naive and $66(46.5 \%)$ had $\leq 1$ previous negative set of random TRUS-GB findings. The MRI-GB findings were positive in 75 of 142 patients with a DR of $52.8 \%$. Of the 76 patients with $\leq 1$
\end{abstract}

\section{KARGER}

Fax +4161306 1234

E-Mail karger@karger.com

www.karger.com
(C) 2020 The Author(s)

Open access

This article is licensed under the Creative Commons AttributionNonCommercial-NoDerivatives 4.0 International License (CC BYNC-ND) (http://www.karger.com/Services/OpenAccessLicense) Usage and distribution for commercial purposes as well as any distribution of modified material requires written permission. previous set of TRUS-GB, 43 had PCa found by MRI-GB, with a DR of $57.3 \%$. The DR in the 66 biopsy-naive patients was $48 \%$ $(32 / 66)$. Of the 75 patients with positive biopsy findings, 54 $(80.5 \%)$ were found to have csPCa on histological examination. Of these 54 patients, 28 had an International Society of Urological Pathology grade 2; 5 had grade 3, 19 had grade 4, and 2 had grade 5 . Considering the anatomic distribution of the index lesions using the PI-RADS v2 scheme, the probability of PCa was greater for lesions located in the peripheral zone $(55$ of $75,73.3 \%)$ than for those in the central zone (20 of $75,26.7 \%)$. Conclusions: Our study conducted on 142 patients confirmed the greater DR of csPCa by MRI-GB, with a very low number of cores needed and a negligible incidence of complications, especially in patients with a previous negative biopsy. MRI-GB is optimal for the diagnosis of anterior and central lesions.

(C) 2020 The Author(s)

Published by S. Karger AG, Basel

\section{Introduction}

Prostate cancer (PCa) is the principal neoplasm diagnosed in men after 65 years of age [1]. In suspected cases a random transrectal ultrasound-guided biopsy (TRUS-

Daniele D'Agostino

Department of Urology, Abano Terme Hospital 
GB) is the current reference standard procedure for diagnosis [2], but this procedure has limitations related to the low detection rate (DR) described in the literature. From a radiological point of view, $\mathrm{PCa}$ is isoechoic or slightly hypoechoic in $37-50 \%$ of cases, and this makes it not always ecographically identifiable [3]. Moreover, the distribution of the neoplasm is not homogeneous in the gland and in a non-negligible percentage of cases (25-30\%), it can arise from the anterior part of the gland (anterior horn of the peripheral gland, central or transitional zones, and fibromuscular stroma). Thus, a random TRUS-GB can miss $40-50 \%$ of PCa cases $[4,5]$, with a relevant number of clinically significant tumors, especially in larger glands. An increase of sampling can improve the overall DR, but this may lead to an increase in the overdiagnosis of non-clinically significant diseases and on the other hand an increase in the morbidity associated with the procedure. In fact, the risk of complications especially increases with an increase of the number of cores taken [6]. In patients with a previous negative biopsy with persistent clinical suspicion of $\mathrm{PCa}$, the choice of the correct diagnostic approach remains an open question. The DR decreases with repeated biopsies (10-20\% for the second mapping and 5-9\% for the third) [7, 8]. In the diagnosis and staging of PCa other imaging technique are used [9-11] but magnetic resonance imaging (MRI) and in particular multiparametric MRI (mpMRI) has been shown to improve detection, location, and staging of $\mathrm{PCa}[12,13]$. Using T2-weighted imaging and combining functional studies such as diffusion-weighted imaging (DWI), dynamic contrast-enhanced MRI (DCEMRI), or mpMRI improves the identification of $\mathrm{PCa}$ within the gland [14-18]. Numerous studies have highlighted that mpMRI can improve the tumor's risk group classification and could reduce false-negative rates and the necessity for repeat biopsies in both biopsy-naive patients and those with previous negative biopsy findings [19-21]. In particular the use of prostatic MRI-guided biopsy (MRI-GB) techniques [cognitive, MRI/ultrasound (MRI/US) fusion and direct "in-bore" MRI-GB] can improve $\mathrm{PCa}$ detection, especially of clinically significant tumors, which are more frequently under-sampled during random TRUS-GB [22-24]. The introduction of the Prostate Imaging Reporting and Data System (PI-RADS) and in particular the update of version 2 of the PI-RADS score (published in December 2014) represents an important diagnostic tool given the emergence of MRI-GB techniques. The aim of the study was to evaluate the DR, efficiency, and complication rate in a pure "in-bore" MRI-GB series according to PI-RADS v2.

"In-Bore" MRI-Guided Prostate Biopsy

\section{Materials and Methods}

\section{Study Method and Population}

From July 2015 to April 2018, a series of 142 consecutive patients undergoing MRI-GB were prospectively enrolled. Indications for MRI-GB included patients with an elevated prostate-specific antigen (PSA) serum level and/or abnormal digital rectal examination (DRE) findings and $\leq 1$ suspicious area on the mpMRI scan. We included both patient biopsy "naïve" and patient with previous TRUS-GB. According to the European Society of Urogenital Radiology guidelines, the presence of clinically significant PCa (csPCa) on mpMRI is defined as equivocal, likely, or highly likely according to a PI-RADS v2, score of 3, 4, or 5, respectively [25]. The local institutional review board approved the present study.

\section{MRI Examination and Analysis}

All the mpMRI examinations were performed with a $1.5 \mathrm{~T}$ whole body scanner (Achieva XR; Philips Medical Systems, Best, Netherlands) with a 32-channel phased-array surface coil and endorectal coil. After local 3-plane acquisition, required for the correct positioning of the sequences, morphological and functional studies were performed. Morphological studies of the prostate gland were obtained using turbo spin echo T2-weighted sequences (echo time $100 \mathrm{~ms}$, repetition time 4,074 ms, slice thickness $3 \mathrm{~mm}$, slice spacing $0.3 \mathrm{~mm}$, field of view $180 \times 180$ $\mathrm{mm}$, and matrix size $276 \times 205$ ) in the sagittal, axial, and coronal planes, including the seminal vesicles and the entire prostate gland. For the functional study, DWI, DCE-MRI, and magnetic resonance spectroscopic (MRS) acquisitions were performed. DWI acquisition was performed in the axial plane, using a single-shot echo-planar imaging sequence, with 3 b-values $(0,600$, and $1,500 \mathrm{~s} / \mathrm{mm}^{2}$ ), a slice thickness of $3 \mathrm{~mm}$, field of view of $180 \times 180 \mathrm{~mm}$, and matrix size of $80 \times 71$. The DCE-MRI was obtained using a 3-dimensional (3D) T1-weighted, high-resolution isotropic volume examination sequence during the intravenous injection of a contrast bolus of $0.1 \mathrm{mmol} / \mathrm{kg}$ body weight of meglumine gadobenate (MultiHance, Bracco Diagnostics Inc., Milan, Italy) at a flow rate of $3.5 \mathrm{ml} / \mathrm{s}$, followed by $15 \mathrm{ml}$ of saline solution. Twenty-three 3D data sets, 1 before and 22 after contrast administration were acquired with a 10 second temporal resolution and a total duration of 4 minutes (depending on the volume of the prostate gland). The first data set acquired before contrast agent administration, was used to detect any residual blood from the previous biopsy. The MRS was obtained using the 3D chemical shift imaging sequence with the following parameters: matrix $10 \times 10 \times 12$ phase-encoding steps with a nominal voxel size of $<0.5 \mathrm{~cm}^{3}$, spectral selective suppression of water and lipid signals, and an interactive automatic shimming up to a line width at half height of the water resonance peak of 15 to $20 \mathrm{~Hz}$. The volume of interest was aligned to the axial T2-weighted images and centered on each prostate to maximize coverage of the whole gland, thus minimizing contamination by the surrounding tissue. Finally, a turbo spin echo T2-weighted sequence (echo time 100 $\mathrm{ms}$, repetition time $3,445 \mathrm{~ms}$, slice thickness $4 \mathrm{~mm}$, slice spacing $0.4 \mathrm{~mm}$, field of view $260 \times 260 \mathrm{~mm}$, and matrix size $260 \times 178$ ) in the axial plane was acquired from the aortic bifurcation to the symphysis pubis in order to evaluate the pelvic lymph nodes and bone. All the mpMRI scans were assessed by 1 reader (M.V.) with 10 years of specific experience in prostate MRI who was unaware 
Table 1. Clinical and radiological features of patients undergoing in-bore biopsy

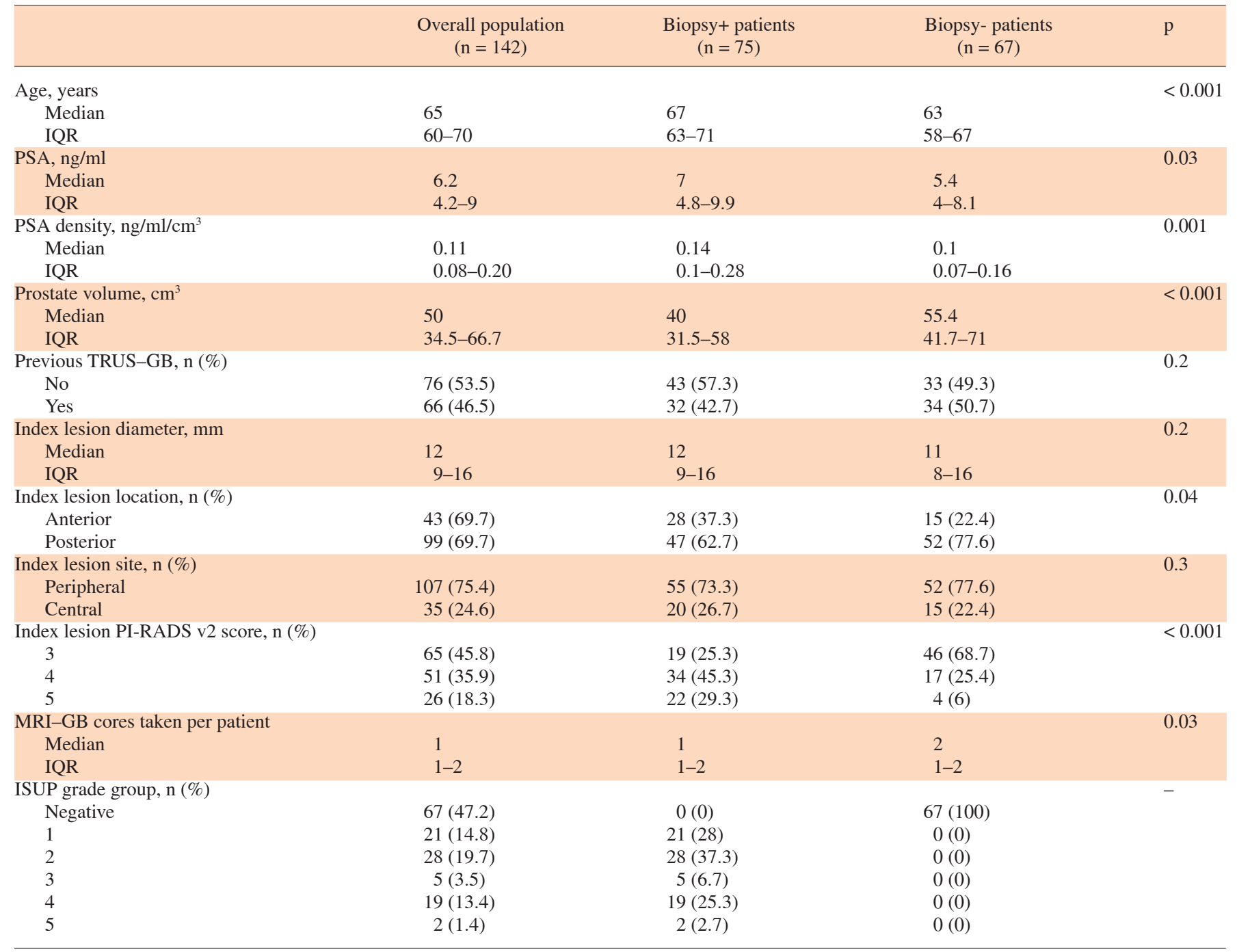

of the patient information. The DWI and DCE-MRI scans were processed using an independent workstation with dedicated software (ViewForum, Philips Medical Systems). Regions of interest positioned on the suspected areas were used to calculate the corresponding value of the apparent diffusion coefficient for DWI. Semiquantitative MRI perfusion was performed using the same workstation with analysis of DCE-MRI data sets and signal intensity-time curve generation. For MRS, spectral information was overlaid on T2-weighted images. The relevant metabolites were citrate (a marker of benign tissue), creatine (insignificant for diagnosis but difficult to resolve from choline), and choline (a marker of malignant tissue). In quantitative analysis, for each available voxel, the absolute values (in parts per million) of choline, creatine, and citrate were calculated, and the peak integrals of all metabolites were estimated as the choline plus creatine to citrate ratio. Using qualitative analysis, the peak heights of citrate and choline were visually compared. All lesions were scored using the PI-RADS v2 score according to the European Society of Urogenital Radiology guidelines for evaluation and reporting of prostate mpMRI findings [24]. For each patient, the index lesion was defined as the lesion with the greatest PI-RADS v2 score. In the case of $\leq 2$ lesions with the highest PI-RADS v2 score, the one with extra-prostatic extension was considered as the index lesion. If no extra-prostatic extension was found, the largest of the tumors was considered the index lesion [25].

\section{Biopsy Procedure}

The biopsies were transrectally performed, within 2 weeks of the mpMRI, by a single urologist with considerable experience in MRI-GB, using the 1.5T MRI scanner (Achieva XR, Philips Medical Systems), with the patients in the prone position. An 18-guage automatic core needle and a titanium double-shot bi- 
Table 2. Location of index lesion by mpMRI and bioptic results stratified according to previous biopsy status and bioptic findings

\begin{tabular}{|c|c|c|c|c|}
\hline & & $\begin{array}{c}\text { Biopsy+ patients } \\
(\mathrm{n}=75)\end{array}$ & $\begin{array}{c}\text { Biopsy- patients } \\
\quad(\mathrm{n}=67)\end{array}$ & $\mathrm{p}$ \\
\hline \multirow{6}{*}{$\begin{array}{l}\text { Biopsy näive patients } \\
(\mathrm{n}=76)\end{array}$} & Index lesion location, $\mathrm{n}(\%)$ & & & \multirow[t]{3}{*}{0.1} \\
\hline & Anterior & $7(16.3)$ & $10(30.3)$ & \\
\hline & Posterior & $36(83.7)$ & $23(69.7)$ & \\
\hline & Index lesion site, $\mathrm{n}(\%)$ & & & \multirow[t]{3}{*}{0.5} \\
\hline & Central & $10(23.3)$ & $9(27.3)$ & \\
\hline & Peripheral & $33(76.7)$ & $24(72.7)$ & \\
\hline \multirow{6}{*}{$\begin{array}{l}\text { Previous negative biopsies } \\
(\mathrm{n}=66)\end{array}$} & Index lesion location, $\mathrm{n}(\%)$ & & & \multirow[t]{3}{*}{0.001} \\
\hline & Anterior & $13(40.6)$ & $5(14.7)$ & \\
\hline & Posterior & $19(59.4)$ & $29(85.3)$ & \\
\hline & Index lesion site, $\mathrm{n}(\%)$ & & & 0.02 \\
\hline & Central & $14(43.8)$ & $6(17.6)$ & \\
\hline & Peripheral & $18(56.3)$ & $28(82.4)$ & \\
\hline
\end{tabular}

opsy gun were used. All patients received oral antibiotic prophylaxis with ciprofloxacin $500 \mathrm{mg}$ twice daily, starting from the day before the procedure and for 2 days after. Before biopsy, DRE was performed to evaluate any anatomic or pathological condition that could hinder transrectal biopsy and to approximate the position of the gland. A periprostatic nerve blockade for local anesthesia with lidocaine $2 \%$ was administered before the biopsy. Axial and sagittal T2-weighted images were obtained to visualize the prostate and identify the target lesion. For the MRI-GB, a nonmagnetic portable biopsy device (DynaTRIM, Invivo, Gainesville, FL) and a dedicated software package for device tracking and target location (DynaCAD, Invivo, Gainesville, FL) were also used. These tools allow one to direct the needle, which is visible on the MRI scans because of the gadolinium inserted into the needle guide, within the target lesion using a 3D system for alignment of the biopsy arm in the space. Multiple T2-weighted acquisitions in the axial and sagittal planes along the axis of the needle allow one to assess the correct position with respect to the target lesion in order to establish the direction and depth of the needle movements. These procedures can be repeated more than once, if targeting is not certain, according to the lesion size or subjective judgment of the operator. Only the index lesion in each patient was scheduled for the MRI-GB. The number of cores taken was related to the size of the lesion. The cores were taken out along the long axis of the lesion, with a maximum of 2 biopsies taken for each needle. Finally, the patients were evaluated 1 hour and 7 to 10 days after the procedure to evaluate and record possible complications. The specimens were processed by routine pathological fixation with formalin solution and evaluated by a single dedicated uropathologist with 20 years of experience. Cancer cells retrieved in the MRI-GB specimens were used as the reference standard to determine the positivity of the biopsy. The criteria for clinical significance concerning PCa was an International Society of Urological Pathology prognostic group disease $\geq 2$.

\section{Statistical Analysis}

Each statistical evaluation was performed using the Statisti-

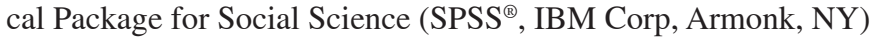
v21 for Macintosh ${ }^{\circledR}$. Continuous and categorical variables were reported as medians with interquartile range (IQR) and frequencies with percentages, respectively. The Mann-Whitney test and Pearson's Chi-Square test were used to test the association between continuous and categorical variables, respectively.

Uni- and multi-variate Logistic Regression models with the enter method were used to investigate predictors of $\mathrm{PCa}$ and $\mathrm{csPCa}$ detection by the MRI-GB. Two-tailed $\mathrm{p}<0.05$ were considered statistically significant.

\section{Results}

The clinical, radiological, and pathological characteristics of the entire population are listed in table 1 . Of 142 patients, $76(53.5 \%)$ were biopsy naive and $66(46.5 \%)$ had $\leq 1$ previous negative set of random TRUS-GB findings. The median diameter of the index lesion was 12 mm (range: 3-32 mm, IQR: 9-16 mm). The MRI-GB findings were positive in 75 of 142 patients with a DR of $52.8 \%$. Of the 76 patients with $\leq 1$ previous set of TRUS-GB, 43 had PCa found by MRI-GB, with a DR of $57.3 \%$. The DR in the 66 biopsy-naive patients was $48 \%$ (32 of 66). The total PSA level and PSA density were significantly greater in patients with positive MRIGB findings ( $\mathrm{p}<0.001$ for density). Of the 75 patients with positive biopsy findings, $54(80.5 \%)$ were found to have csPCa on histological examination. Of these 54 patients, 28 had International Society of Urological Pathology grade 2, 5 had grade 3, 19 had grade 4, and 2 had grade 5. Regarding the PI-RADS v2 score, the patients diagnosed with PCa had a PI-RADS v2 score that was significantly greater than those with negative biopsy findings $(\mathrm{p}<0.001)$. Overall, in patients with a PI-RADS v2 score of 3,4 , and $5, \mathrm{PCa}$ was retrieved in

"In-Bore” MRI-Guided Prostate Biopsy 
Table 3. Uni- and multi-variate logistic regression model predicting PCa by MRI-GB $(n=75)$



19, 34, and 22 cases, respectively. Overall, considering the anatomic distribution of the index lesions using the PI-RADs v2 scheme, the probability of PCa was greater for lesions located in the peripheral zone $(55 / 75,73.3 \%)$ than for those in the central zone $(20 / 75,26.7 \%)$. The distribution of positive lesions according to the location is listed in table 2 . In the subset of the 76 biopsy-naive patients, the proportion of $\mathrm{PCa}$ retrieved in the anterior lesions $(7 / 43,16.3 \%)$ was less than that observed in the posterior lesions $(36 / 43,83.7 \%)$. PCa was more likely to be found in the peripheral zone $(76.7 \%)$ than in the central zone $(23.3 \%)$, but the difference was not statistically significant. In contrast, in the 66 men with $\leq 1$ previous biopsy, the proportion of tumors found in the central and anterior sites of the gland was significantly greater. PCa was found in 14 of the centrally located lesions (43.8\%) compared with 18 peripheral lesions $(56.3 \%, \mathrm{p}<0.02)$. MRI-GB revealed PCa in 13 anterior lesions (40.6\%) compared with 19 lesions $(59.4 \%)$ located in the posterior sites of the gland $(p<0.001)$. In the 32 men with positive MRI-GB findings, the correlation between the PI-RADS v2 score and Gleason score in the MRI-GB cores was statistically significant (R $0.839,95 \%$ confidence interval $[\mathrm{CI}], 0.535-0.951$, p 0.003). Stratifying the index lesions according to the median diameter of 12 $\mathrm{mm}, 2$ groups were identified: 28 lesions $>12 \mathrm{~mm}$ and 42 lesions $\leq 12 \mathrm{~mm}$. The MRI-GB cores were more likely to be positive in the latter group (54.7 vs. $32.2 \%$ for lesions $\leq 12 \mathrm{~mm}$ and $>12 \mathrm{~mm}$, respectively), with a slight statistical significance (p 0.058).

On uni-variate analysis, age $\leq 65$ years $(\mathrm{p}<0.001)$, PSA density $\leq 0.15 \mathrm{ng} / \mathrm{ml} / \mathrm{cm}^{3}(\mathrm{p}<0.01)$, PI-RADS 4 $(\mathrm{p}<0.001)$, and PI-RADS $5(\mathrm{p}<0.001)$ correlated with biopsy positivity. Multi-variate analysis showed that only PI-RADS 4 and PI-RADS 5 (hazard ratio [HR], 4.69, 95\%CI 0.92-23.74) were independent predictors of MRI-GB positivity (P 0.04, table 3). Similarly, a PIRADS 4 (HR, 7.09, 95\%CI 1.45-34.73) and 5 (HR, 9.14, 95\% CI 0.77-48.49) were independent predictors of csPCa on multi-variate analysis (P 0.02 and P 0.04 , respectively; table 4$)$. No complications were observed during the procedures.

\section{Discussion}

TRUS-GB remains the gold standard for the primary diagnosis of PCa. In some cases (about 20\%) PCa is not detected at the first biopsy; but high-grade prostatic intraepithelial neoplasia, atypical small acinar proliferation can be found in the initial histology. Persistent high or rising PSA or a suspect finding in DRE are recommenda- 
Table 4. Uni- and multi-variate logistic regression model predicting csPCa by MRI-GB $(\mathrm{n}=54)$

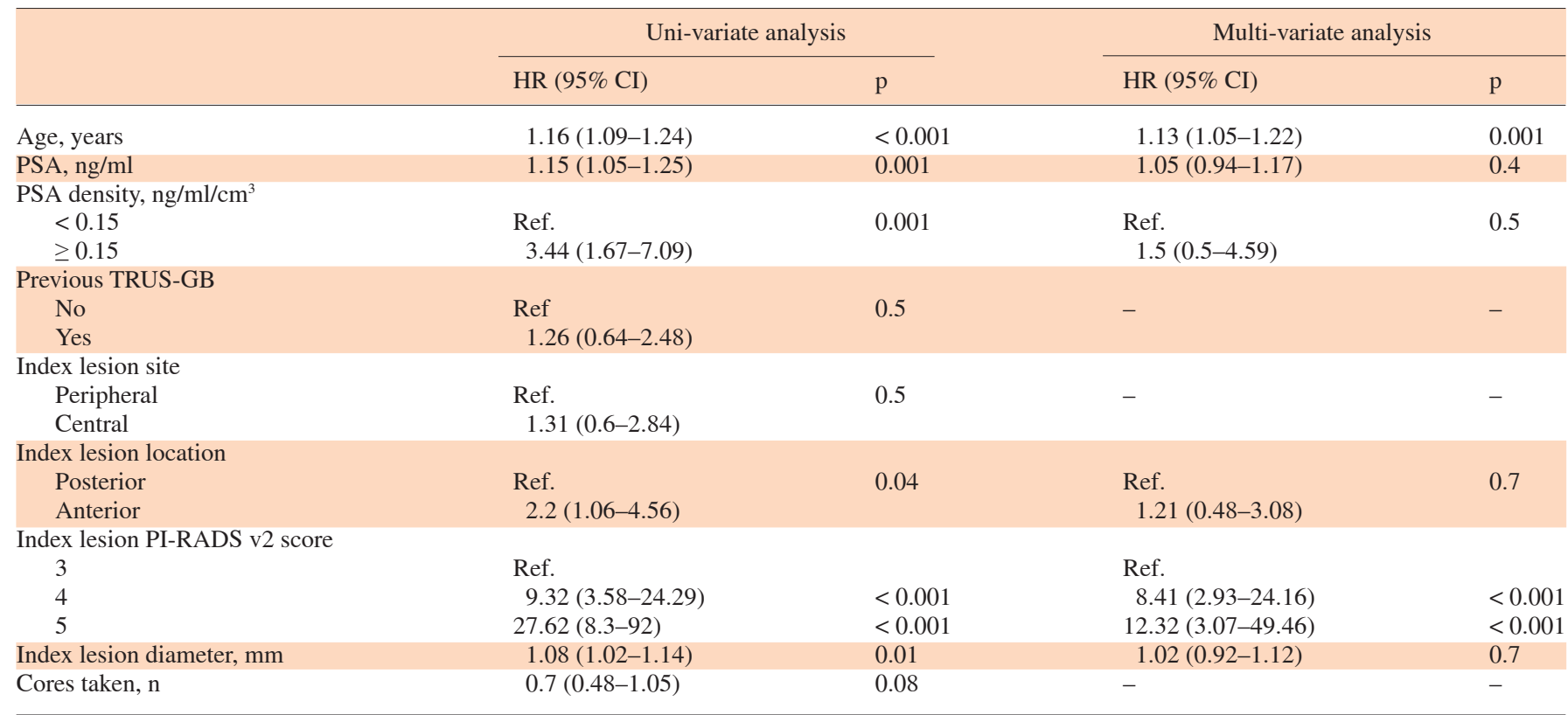

tions for re-biopsy, which has a DR between 20 and $35 \%$ [26-28]. Moreover, re-biopsies improve DR of PCa, so solely increasing the number of biopsy cores may also contribute to the detection of clinically insignificant disease with significant repercussions in terms of the quality of life [29-31]. Lastly, during the TRUS-GB, the lesions of the posterior region of the prostate are sampled while the anterior and central lesions are almost never sampled. mpMRI allows for the accurate detection and location of csPca. Actually, mpMRI is recommended by the European Association of Urology in men with a persistent clinical suspicion of PCa despite a negative TRUS-GB [32]. Presenting preliminary data on 70 patients we highlighted that MRI-GB resulted in the greater detection of PCa, with a very low number of cores needed and a negligible incidence of complications [33]. The new results of the study, conducted on 142 patients showed that MRI-GB has a high DR for csPCa (PI-RADS v2 score correlated) with a low number of cores taken, especially for lesions located in the central and anterior regions of the prostate. MRI-GB can potentially reduce the sampling error associated with conventional biopsy by providing better disease location and characterization. Several MRI-GB methods have been proposed. In the cognitive technique, TRUS-GB is planned using a mental reconstruction of MRI scans provided by the operator.

"In-Bore" MRI-Guided Prostate Biopsy
Despite the reduced costs, this method has a long learning curve and is extremely dependent on the physician's expertise to obtain an accurate sampling of the index lesions. The DR of PCa for cognitive technique increases with the PI-RADS score, particularly when PI-RADS 4 and 5 are biopsied. MRI/US fusion biopsy is a method to align a pre-registered MRI scan with an intraprocedural ultrasound scan in order to identify and target suspected lesions within the gland through dedicated hardware platforms targeting areas found during mpMRI and not clearly visible during ultrasound scanning. MRI/US fusion guided biopsy has higher sensitivity, accuracy, and specificity than a TRUS-GB and no significant difference for the treatment zone between combined biopsies and targeted areas. Another advantage of the fusion technique is the ability to perform a systematic biopsy during the same session, because $\leq 16 \%$ of men have no suspicious signs. The "in-bore" MRI-GB technique is carried out within the mpMRI scanner, and diagnostic quality images used to identify areas of interest are registered with the interventional images (often acquired at $1-1.5 \mathrm{~T}$ ). The target lesion is biopsied using non-magnetic guidance from serial scans during the procedure. The advantages consist of real-time feedback with needle placement, fewer sampled cores, and a low likelihood of missing the target. The disadvantages of "in-bore" MRI include the 
longer operative time, higher costs, initial expertise required with the software dedicated to drive the targeted cores, and the inability to perform concomitant systematic TRUS-GB. Our experience with MRI-GB conducted on 142 patents confirmed the feasibility and reproducibility of an "in-bore" strategy with a 1.5T MRI scanner using a 32-channel coil. Both 1.5 and 3T scanners are currently used for $\mathrm{PCa}$ detection, with the latter becoming increasingly preferred, owing to the higher signal/ noise ratio and consequently, improved image quality. A comparison between the diagnostic performance of the 2 systems is lacking, although many investigators [34-38] have obtained comparable results, even with various technological equipment and experience levels. Many factors affect image quality other than the magnetic field strength. Thus, optimization of the acquisition parameters and the use of appropriate contemporary technology are very important in obtaining adequate and reliable diagnostic examination findings [25]. The overall DR $(52.8 \%)$ in the present study was high and higher than previous reports considering men with a $\leq 1$ previous set of TRUS-GB (DR 41.5\%) [21, 39-42]. Furthermore, it is very important to highlight that $54 / 75$ patients $(72 \%)$ were found to have csPCa. Although we cannot yet recommend mpMRI as a first-line diagnostic tool in every case owing to its low availability and high costs [2], the use of a targeted biopsy can be suggested in a repeat biopsy setting because it can achieve a significantly greater cancer DR, overcoming those reported with repeat systematic biopsies $[6,7]$. In particular, in the series of patients with previous negative biopsies, we observed that a significant proportion of tumors found in the central and anterior sites of the gland was significantly greater $(\mathrm{p}<0.001$ for the anterior lesion). This data shows the importance of mpMRI in the location of lesions in the anterior and central region of the prostate, especially in patients with previous negative biopsies. Hambrock et al. [41] reported a cancer DR of 59\%, of which $93 \%$ were clinically significant in 68 men with $\leq 2$ TRUS-GB findings who had undergone mpMRI and then MRI-GB. When comparing the MRI-GB group with a matched reference group who had undergone repeat TRUS-GB, MRI-GB detected significantly more tumors than the standard repeated TRUS-GB (22\% in the second and $15 \%$ in the third TRUS-GB). More recently, in their preliminary experience with the "in-bore" technique using a $1.5 \mathrm{~T}$ magnet equipped with a 32-channel body coil and an endorectal coil, Panebianco et al. [43] showed a DR of $80 \%$ for $\mathrm{PCa}$ in 23 patients with 2 cores obtained for each patient. Remarkably, $90 \%$ of these PCa lesions had a Gleason score $\leq 7$. These percentages were greater than those reported in previous series with the same equipment, although the inclusion criteria were slightly more selective. However, the number of patients with a history of previous TRUS-GB was not reported. Furthermore, our experience reinforces 2 important issues related to the MRI-GB technique. First, the superiority of MRI-GB compared with TRUS-GB to decrease the detection of low-risk PCa. As reported in a recent review, MRI-GB resulted in greater detection of significant $\mathrm{PCa}$ compared with standard TRUS-GB (relative sensitivity $1.26,95 \%$ CI 1.08-1.46) [16]. The ability of MRI to prevent unnecessary TRUS-GB and reduce overtreatment could lead to lower costs and greater quality of life when the costs of follow-up and treatment are considered. In addition, the "in-bore" MRI-GB has the great advantage of real-time feedback for needle placement and correct sampling of the lesion compared with other MRI-guided procedures (cognitive technique and MRI/US fusion), avoiding mistakes in sampling and potentially reducing false-negative results. However, in our cohort, among the patients with negative findings, $17(25.4 \%)$ and $4(6 \%)$ had PI-RADS 4 and 5 respectively. In respect to the preliminary cohort [33], the false-negative rates related to the initial learning curve of the procedure were improved. Otherwise, the limits of mpMRI in the diagnosis of PCa are still evident. Anterior PCa lesions remains a diagnostic challenge considering their underestimated frequency. Several series have demonstrated the high capability of mpMRI to detect PCa lesions located in the anterior regions of the prostate that are missed by standard TRUS-GB $[44,45]$. In our study we observed a significant rate of anterior tumors of the prostate especially in patients with a previous negative TRUS-GB. Ouzzane et al. [46] reported that the detection of PCa was improved by performing targeted cores after mpMRI. In a cohort of 324 patients who underwent mpMRI and 26core (transperineal 14-core plus transrectal 12-core) biopsy, Komai et al. [47] found that $20 \%$ of men harbored an anterior lesion and on targeted biopsy, $86 \%$ were proved to have $\mathrm{PCa}$. Moreover, $40 \%$ of $\mathrm{PCa}$ lesions were missed during the rst set of 12-core biopsy. However, accurate sampling of the anterior region of the gland is not practical using a TRUS-guided approach. The correlation between the PI-RADS v2 score of mpMRI and csPCa are highlighted in our results. These data show the good diagnostic performance of the MRI-GB procedure and the high capability of mpMRI to predict the biological aggressiveness of neoplastic lesions. However, a significant percentage of patients with no suspicious MRI 
target were found to have csCPa on systematic biopsy [25]; For this reason the inability to perform concomitant systematic TRUS-GB in conjunction with MRI-GB is a limitation of the "in-bore" technique, especially in biopsy-naive patients. The overall PCa DR and DR of csPCa are greatest when targeted biopsy and systematic biopsy are evaluated in conjunction with each other [47]. The additional findings of systematic biopsy reflect the multifocality of PCa. Therefore, the combination of both biopsy methods represent the best approach for the prediction of the final tumor grade. In contrast, in patients with previous negative biopsy findings and persistent $\mathrm{PCa}$ suspicion, MRI-GB without repeat systemic biopsy could represent the best management after recent and adequate systemic prostate sampling. In spite of having increased the number of patients compared to the preliminary study the present study was not devoid of limitations comparable to the previous study (the number of patients, patients included only those men with positive findings at mpMRI, no follow-up data, and no prostate specimen histological examinations that could confirm the results of negative MRI-GB findings). However, we believe that this study confirms even more the fundamental role of MRI and in particular of the "in-bore" MRI$\mathrm{GB}$ in the diagnosis of $\mathrm{PCa}$, in particular in patients with previous negative TRUS-GB, selecting with greater precision the csPCa in these patients.

\section{Conclusions}

After the preliminary evaluation on 70 cases, our study conducted on 142 patients confirmed the greater DR of csPCa of MRI-GB, with a very low number of cores needed and a negligible incidence of complications, especially in patients with a previous negative biopsy, MRI-GB is optimal for the diagnosis of anterior and central lesions. Further data are needed to evaluate the clinical results compared with those from systematic, cognitive, or fusion biopsy.

\section{References}

1 Siegel R, Naishadham D, Jemal A: Cancer statistics 2012. CA Cancer J Clin 2012;62: $10-21$.

- 2 Heidenreich A, Bastian PJ, Bellmunt J, Bolla M, Joniau S, van der Kwast T, Mason M, Matveev V, Wiegel T, Zattoni F, Mottet $\mathrm{N}$ : EAU guidelines on prostate cancer, part 1: screening, diagnosis, and local treatment with curative intent-update 2013. Eur Urol 2014;65:124-137.

- 3 Vo T, Rifkin MD, Peters TL: Should ultrasound criteria of the prostate be redefined to better evaluate when and where to biopsy. Ultrasound Q 2001;17:171-176.

4 Jones JS: Saturation biopsy for detecting and characterizing prostate cancer. BJU Int 2007; 99:1340-1344.

-5 Lane BR, Zippe CD, Abouassaly R, Schoenfield L, Magi-Galluzzi C, Jones JS: Saturation technique does not decrease cancer detection during follow up after initial prostate biopsy. J Urol 2008;179:1746-1750.

-6 Borghesi M, Ahmed H, Nam R, Schaeffer E, Schiavina R, Taneja S, Weidner W, Loeb $\mathrm{S}$ : Complications after systematic, random, and image-guided prostate biopsy. Eur Urol 2017;71:353-365.
7 Djavan B, Ravery V, Zlotta A, Dobronski P, Dobrovits M, Fakhari M, Seitz C, Susani M, Borkowski A, Boccon-Gibod L, Schulman CC, Marberger M: Prospective evaluation of prostate cancer detected on biopsies 1, 2, 3 and 4: when should we stop? J Urol 2001; 166:1679-1683.

8 Shariat SF, Roehrborn CG: Using biopsy to detect prostate cancer. Rev Urol 2008;10: 262-280.

-9 Schiavina R, Chessa F, Borghesi M, Gaudiano C, Bianchi L, Corcioni B, Castellucci P, Ceci F, Ceravolo I, Barchetti G, Del Monte M, Campa R, Catalano C, Panebianco V, Nanni C, Fanti S, Minervini A, Porreca A, Brunocilla E: State-of-the-art imaging techniques in the management of preoperative staging and re-staging of prostate cancer. Int J Urol 2019;26:18-30.

10 Vagnoni V, Brunocilla E, Bianchi L, Porreca $\mathrm{A}$, Borghesi $\mathrm{M}$, Pultrone $\mathrm{CV}$, Angelo $\mathrm{P}$, Chessa F, Ceci F, Mengoni F, Dababneh H, Castellucci P, Fanti S, Martorana G, Schiavina R: State of the art of PET/CT with 11-choline and $18 \mathrm{~F}$-fluorocholine in the diagnosis and follow-up of localized and locally advanced prostate cancer. Arch Esp Urol 2015;68:354-370.
1 Schiavina R, Bianchi L, Mineo Bianchi F, Borghesi M, Pultrone CV, Dababneh $\mathrm{H}$, Castellucci P, Ceci F, Nanni C, Gaudiano C, Fiorentino M, Porreca A, Chessa F, Minervini A, Fanti S, Brunocilla E: Preoperative staging with $11 \mathrm{C}$-choline PET/CT is adequately accurate in patients with very highrisk prostate cancer. Clin Genitourin Cancer 2018;16:305-312.

-12 McClure TD, Margolis DJ, Reiter RE, Sayre JW, Thomas MA, Nagarajan R, Gulati M, Raman SS: Use of MR imaging to determine preservation of the neurovascular bundles at robotic assisted laparoscopy prostatectomy. Radiology 2012;262:874-883.

13 Tan N, Margolis DJ, McClure TD, Thomas A, Finley DS, Reiter RE, Huang J, Raman SS: Radical prostatectomy: value of prostate MRI in surgical planning. Abdom Imaging 2012;37:664-674.

14 Villers A, Puech P, Mouton D, Leroy X, Ballereau C, Lemaitre L: Dynamic contrast enhanced, pelvic phased array magnetic resonance imaging of localized prostate cancer for predicting tumor volume: correlation with radical prostatectomy findings. J Urol 2006; 176:2432-2437.

\footnotetext{
“In-Bore” MRI-Guided Prostate Biopsy
} 
15 Delongchamps NB, Rouanne M, Flam T, Beuvon F, Liberatore M, Zerbib M, Cornud F: Multiparametric magnetic resonance imaging for the detection and localization of prostate cancer: combination of T2-weighted, dynamic contrast-enhanced and diffusion-weighted imaging. BJU Int 2011;107: 1411-1418.

Testa C, Schiavina R, Lodi R, Salizzoni E,

$\checkmark 16$ Tonon C, D'Errico A, Corti B, Morselli-Labate AM, Franceschelli A, Bertaccini A, Manferrarik F, Grigioni WF, Canini R, Martorana G, Barbiroli B: Accuracy of MRI/ MRSI-based transrectal ultrasound biopsy in peripheral and transition zones of the prostate gland in patients with prior negative biopsy. NMR Biomed 2010;23:1017-1026.

Baccos A, Schiavina R, Zukerman Z, Busato

$\checkmark 17$ F, Gaudiano C, Salizzoni E, Fiorentino M, Golfieri R, Martorana G: Accuracy of endorectal magnetic resonance imaging (MRI) and dynamic contrast enhanced-MRI (DCE$\mathrm{MRI})$ in the preoperative local staging of prostate cancer. Urologia 2012;79:116-122. Testa C, Schiavina R, Lodi R, Salizzoni E,

-18 Corti B, Farsad M, Kurhanewicz J, Manferrari $\mathrm{F}$, Brunocilla $\mathrm{E}$, Tonon $\mathrm{C}$, Monetti $\mathrm{N}$, Castellucci P, Fanti S, Coe M, Grigioni WF, Martorana G, Canini R, Barbiroli B: Prostate cancer: sextant localization with MR imaging, MR spectroscopy, and 11C-choline PET/ CT. Radiology 2007;244:797-806. Watanabe Y, Terai A, Araki T, Nagayama M,

- 19 Okumura A, Amoh Y, Ishimori T, Ishibashi M, Nakashita S, Dodo Y: Detection and localization of prostate cancer with the targeted biopsy strategy based on ADC map: a prospective large-scale cohort study. J Magn Reson Imaging 2012;35:1414-1421. Schiavina R, Bianchi L, Borghesi M, Dabab-

20 neh H, Chessa F, Pultrone CV, Angiolini A, Gaudiano C, Porreca A, Fiorentino M, De Groote R, D'Hondt F, De Naeyer G, Mottrie A, Brunocilla E: MRI displays the prostatic cancer anatomy and improves the bundles management before robot-assisted radical prostatectomy. J Endourol 2018;32:315-321. Hoeks CM, Schouten MG, Bomers JG,

-21 Hoogendoorn SP, Hulsbergen-van de Kaa CA, Hambrock T, Vergunst H, Sedelaar JP, Fütterer JJ, Barentsz JO: Three-Tesla magnetic resonance-guided prostate biopsy in men with increased prostate-specific antigen and repeated, negative, random, systematic, transrectal ultrasound biopsies: detection of clinically significant prostate cancers. Eur Urol 2012;62:902-909.

Schiavina R, Borghesi M, Brunocilla E, Ro-

-22 magnoli D, Diazzi D, Giunchi F, Vagnoni $\mathrm{V}$, Pultrone CV, Dababneh $\mathrm{H}$, Porreca A, Fiorentino M, Martorana G: The biopsy Gleason score $3+4$ in a single core does not necessarily reflect an unfavourable pathological disease after radical prostatectomy in comparison with biopsy Gleason score $3+3$ : looking for larger selection criteria for active surveillance candidates. Prostate Cancer Prostatic Dis 2015;18:270-275.
23 Grasso AA, Cozzi G, DE Lorenzis E, Ceruti C, Crivellaro S, Falsaperla M, Minervini A, Masieri L, Porreca A, Zaramella S, Rocco B: Multicenter analysis of pathological outcomes of patients eligible for active surveillance according to PRIAS criteria. Minerva Urol Nefrol 2016;68:237-241.

24 Vagnoni V, Bianchi L, Borghesi M, Pultrone CV, Dababneh H, Chessa F, La Manna G, Rizzi S, Porreca A, Brunocilla E, Martorana G, Schiavina R: Adverse features and competing risk mortality in patients with highrisk prostate cancer. Clin Genitourin Cancer 2017; 15:e239-e248.

25 Weinreb JC, Barentsz JO, Choyke PL, Cornud F, Haider MA, Macura KJ, Margolis D, Schnall MD, Shtern F, Tempany CM, Thoeny HC, Verma S: PI-RADS prostate imaging reporting and data system: 2015, version 2 . Eur Urol 2016;69:16-40.

26 Postma R, Roobol M, Schroder FH, van der Kwast TH: Lesions predictive for prostate cancer in a screened population: first and second screening round findings. Prostate 2004; 61:260-266.

27 Roehl KA, Antenor JA, Catalona WJ: Serial biopsy results in prostate cancer screening study. J Urol 2002;167:2435-2439.

28 Applewhite JC, Matlaga BR, McCullough DL: Results of the 5 region prostate biopsy method: the repeat biopsy population. J Urol 2002;168:500-503.

29 Porreca A, Noale M, Artibani W, Bassi PF, Bertoni F, Bracarda S, Conti GN, Corvò R, Gacci M, Graziotti P, Magrini SM, Mirone V, Montironi R, Muto G, Pecoraro S, Ricardi U, Russi E, Tubaro A, Zagonel V, Crepaldi G, Maggi S: Disease-specific and general health-related quality of life in newly diagnosed prostate cancer patients: the Pros-IT CNR study. Health Qual Life Outcomes 2018;16:122

30 Gacci M, Noale M, Artibani W, Bassi PF, Bertoni F, Bracarda S, Conti GN, Corvò R, Graziotti P, Magrini SM, Mirone V, Montironi R, Muto G, Pecoraro S, Porreca A, Ricardi U, Russi E, Tubaro A, Zagonel V, Crepaldi G, Maggi S: Quality of life after prostate cancer diagnosis: data from the Pros-IT CNR. Eur Urol Focus 2017;3:321-324.

-31 Noale M, Maggi S, Artibani W, Bassi PF, Bertoni F, Bracarda S, Conti GN, Corvò R, Gacci M, Graziotti P, Magrini SM, Maurizi Enrici R, Mirone V, Montironi R, Muto G, Pecoraro S, Porreca A, Ricardi U, Tubaro A, Zagonel V, Zattoni F, Crepaldi G: Pros-IT CNR: an Italian prostate cancer monitoring project. Aging Clin Exp Res 2017;29:165-172.

32 Mottet N, Bellmunt J, Bolla M, Briers E, Cumberbatch MG, De Santis M, Fossati N, Gross T, Henry AM, Joniau S, Lam TB, Mason MD, Matveev VB, Moldovan PC, van den Bergh RCN, Van den Broeck T, van der Poel $\mathrm{HG}$, van der Kwast $\mathrm{TH}$, Rouvière $\mathrm{O}$ Schoots IG, Wiegel T, Cornford P: EAUESTRO-SIOG guidelines on prostate cancer. Part 1: screening, diagnosis, and local treat- ment with curative intent. Eur Urol 2017;71: 618-629.

33 Schiavina R, Vagnoni V, D’Agostino D, Borghesi M, Salvaggio A, Giampaoli M, Pultrone CV, Saraceni G, Gaudiano C, Vigo M, Bianchi L, Dababneh H, La Manna G, Chessa F, Romagnoli D, Martorana G, Brunocilla E, Porreca A: "In-bore" MRI-guided prostate biopsy using an endorectal nonmagnetic device: a prospective study of 70 consecutive patients. Clin Genitourin Cancer 2017;15: 417-427.

34 Rosenkrantz AB, Deng FM, Kim S, Lim RP, Hindman N, Mussi TC, Spieler B, Oaks J, Babb JS, Melamed J, Taneja SS: Prostate cancer: multiparametric MRI for index lesion localization - a multiple-reader study. AJR Am J Roentgenol 2012;199:830-837.

-35 Villers A, Puech P, Mouton D, Leroy X, Ballereau C, Lemaitre L: Dynamic contrast enhanced, pelvic phased array magnetic resonance imaging of localized prostate cancer for predicting tumor volume: correlation with radical prostatectomy findings. J Urol 2006; 176:2432-2437.

36 Delongchamps NB, Rouanne M, Flam T, Beuvon F, Liberatore M, Zerbib M, Cornud F: Multiparametric magnetic resonance imaging for the detection and localization of prostate cancer: combination of $\mathrm{T} 2$ weighted, dynamic contrast-enhanced and diffusion-weighted imaging. BJU Int 2011;107: 1411-1418.

37 Testa C, Schiavina R, Lodi R, Salizzoni E, Tonon C, D'Errico A, Corti B, Morselli-Labate AM, Franceschelli A, Bertaccini A, Manferrarik F, Grigioni WF, Canini R, Martorana G, Barbiroli B: Accuracy of MRI/ MRSI-based transrectal ultrasound biopsy in peripheral and transition zones of the prostate gland in patients with prior negative biopsy. NMR Biomed 2010;23:1017-1026.

38 Baccos A, Schiavina R, Zukerman Z, Busato F, Gaudiano C, Salizzoni E, Fiorentino M, Golfieri R, Martorana G: Accuracy of endorectal magnetic resonance imaging (MRI) and dynamic contrast enhanced-MRI (DCEMRI) in the preoperative local staging of prostate cancer. Urologia 2012;79:116-122.

-39 Engelhard K, Hollenbach HP, Kiefer B, Winkel A, Goeb K, Engehausen D: Prostate biopsy in the supine position in a standard 1.5-T scanner under real time MR-imaging control using a MR-compatible endorectal biopsy device. Eur Radiol 2006;16:1237-1243.

40 Roethke M, Anastasiadis AG, Lichy M, Werner M, Wagner P, Kruck S, Claussen CD, Stenzl A, Schlemmer HP, Schilling D: MRI-guided prostate biopsy detects clinically significant cancer: analysis of a cohort of 100 patients after previous negative TRUS biopsy. World J Urol 2012;30:213-218.

41 Hambrock T, Somford DM, Hoeks C, Bouwense SA, Huisman H, Yakar D, van Oort IM, Witjes JA, Fütterer JJ, Barentsz JO: Magnetic resonance imaging guided prostate biopsy in men with repeat negative biopsies 
and increased prostate specific antigen. J Urol 2010;183:520-527.

-42 Jung AJ, Westphalen AC, Kurhanewicz J, Wang ZJ, Carroll PR, Simko JP, Coakley FV: Clinical utility of endorectal MRI-guided prostate biopsy: preliminary experience. J Magn Reson Imaging 2014;40:314-323.

43 Panebianco V, Barchetti F, Manenti G, Aversa T, Catalano C, Simonetti G: MR imaging-guided prostate biopsy: technical features and preliminary results. Radiol Med 2015;120: 571-578.
44 Portalez D, Rollin G, Leandri P, Elman B, Mouly P, Jonca F, Malavaud B: Prospective comparison of T2w-MRI and dynamic contrast-enhanced MRI, 3D-MR spectroscopic imaging or diffusion-weighted MRI in repeat TRUS-guided biopsies. Eur Radiol 2012;20: 2781-2790.

45 Sciarra A, Panebianco V, Ciccariello M, Salciccia S, Cattarino S, Lisi D, Gentilucci A, Alfarone A, Bernardo S, Passariello R, Gentile V: Value of magnetic resonance spectroscopy imaging and dynamic contrast-enhanced imaging for detecting prostate cancer foci in men with prior negative biopsy. Clin Cancer Res 2010;16:1875-1883.
46 Ouzzane A, Puech P, Lemaitre L, Leroy X, Nevoux P, Betrouni N, Haber GP, Villers A: Combined MP-MRI and targeted biopsies improve anterior prostate cancer detection, staging, and grading. Urology 2011;78:13561362.

47 7Komai Y, Numao N, Yoshida S, Matsuoka Y, Nakanishi Y, Ishii C, Koga F, Saito K, Masuda H, Fujii Y, Kawakami S, Kihara K: High diagnostic ability of multiparametric magnetic resonance imaging to detect anterior prostate cancer missed by transrectal 12-core biopsy. J Urol 2013;190:867-873. 